\title{
Pulp capping materials exert an effect on the secretion of IL-1 $\beta$ and IL- 8 by migrating human neutrophils
}

\section{Bruno Neves Cavalcanti(a) Sigmar de Mello Rode ${ }^{(b)}$ Cristiane Miranda França(c) Márcia Martins Marques ${ }^{(a)}$}

(a) Department of Restorative Dentistry, School of Dentistry, Universidade de São Paulo, São Paulo, SP, Brazil.

(b) Department of Prosthetic Dentistry, School of Dentistry, Taubaté University, Taubaté, SP, Brazil.

(c) Postgraduate Program in Rehabilitation Sciences, School of Dentistry, Nove de Julho University, SP, São Paulo, Brazil.

\section{Corresponding author:}

Márcia Martins Marques

Faculdade de Odontologia, Universidade de São Paulo

Av. Prof. Lineu Prestes, 2227

São Paulo - SP - Brazil

CEP 05508-000

E-mail:mmmarques@usp.br

Received for publication on Jun 23, 2010 Accepted for publication on Oct 21, 2010

\begin{abstract}
Pulp repair is a complex process whose mechanisms are not yet fully understood. The first immune cells to reach the damaged pulp are neutrophils that play an important role in releasing cytokines and in phagocytosis. The objective of this study was to analyze the effect of different pulp-capping materials on the secretion of interleukin-1 beta (IL-1 $\beta$ ) and interleukin-8 (IL-8) by migrating human neutrophils. Neutrophils were obtained from the blood of three healthy donors. The experimental groups were calcium hydroxide $\left[\mathrm{Ca}(\mathrm{OH})_{2}\right]$, an adhesive system (Single Bond), and mineral trioxide aggregate (MTA). Untreated cells were used as control. Transwell chambers were used in performing the assays to mimic an in vivo situation of neutrophil chemotaxis. The pulpcapping materials were placed in the lower chamber and the human neutrophils, in the upper chamber. The cells were counted and the culture medium was assayed using ELISA kits for detecting and quantifying IL$1 \beta$ and IL8. The data were compared by ANOVA followed by Tukey's test $(\mathrm{p}<0.05)$. The secretion of IL- 8 was significantly higher in all groups in comparison to the control group $(\mathrm{p}<0.05)$. The adhesive system group showed higher IL-8 than the MTA group ( $<<0.05)$. The secretion of IL$1 \beta$ was significantly greater only in the MTA group $(\mathrm{p}<0.001)$. It was concluded that only MTA is able to improve the secretion of IL-1 $\beta$, and all materials tested increased IL- 8 secretion. These results combined with all the other biological advantages of MTA indicate that it could be considered the material of choice for dental pulp capping.
\end{abstract}

Descriptors: In vitro; Interleukin-8; Interleukin-1; Dental Pulp Capping.

\section{Introduction}

Pulp repair is a complex process whose mechanisms are not yet fully understood. Hard tissue formation is one of the processes requiring further investigation. The first immune cells to reach the damaged pulp are neutrophils that play an important role in releasing cytokines and in phagocytosis. It has been shown that macrophages, mast cells and lymphocytes control neutrophil influx during inflammation by releasing cytokines. The inflammatory process may lead to either dental pulp repair, with or without dentin bridge formation, fibrosis or necrosis. ${ }^{1}$

The successful outcome of restorative treatments requires that pulp repair activity and dentine formation be understood so that treatment 
decisions may be made congruent with the natural repair responses of the tooth. ${ }^{2}$ Pulp capping materials are largely used in dental practice to promote dental pulp repair, especially materials based on calcium hydroxide $\left[\mathrm{Ca}(\mathrm{OH})_{2}\right]$, adhesive systems and, more recently, mineral trioxide aggregates (MTA). ${ }^{3}$

Traditionally, various formulations of $\mathrm{Ca}(\mathrm{OH})_{2}{ }^{-}$ containing materials represent the most usual types of capping treatment. However, the physical limitations of these materials have led researchers and clinicians to seek new materials. ${ }^{4}$

Adhesive systems have expanded the range of possibilities of tooth restoration. However, when in contact with the dental pulp, they may trigger an inflammatory process of varying intensities. Studies dealing with the biocompatibility of adhesive systems with pulp cells are still controversial. Furthermore, they have given little attention to the adverse effects of these materials on innate immune defense cells. ${ }^{5,6}$

MTA has shown good performance as a repair material, by inducing bone, dentine, and cementum deposition. ${ }^{7}$ Compared to $\mathrm{Ca}(\mathrm{OH})_{2}$ cement, MTA has demonstrated a greater ability to maintain the integrity of pulp tissue by inducing the formation of a thicker dentin bridge, with a low inflammatory response. ${ }^{8}$

Although many studies have addressed the effects produced by calcium hydroxide powder, adhesive systems and MTA on cultured fibroblasts, investigations into the effects of these materials on the release of inflammatory cytokines, such as interleukin-1 beta (IL-1 $\beta$ ) and interleukin- 8 (IL-8) by freshly cultured human neutrophils are rare. Bearing in mind the importance of cytokine release to the inflammatory process that takes place prior to dental pulp repair, the aim of this study was to detect and compare the quantity of cytokines released by migrating human neutrophils under the influence of $\mathrm{Ca}(\mathrm{OH})_{2}$, an adhesive system, and MTA.

\section{Materials and Methods Sampling}

Human neutrophils obtained from the blood $(36 \mathrm{ml})$ of three healthy human donors (12 $\mathrm{ml}$ each) were used. The neutrophil pool was obtained using the Percoll gradient method, ${ }^{9}$ re-suspended in cell culture media (Dulbecco's modified Eagle Medium, DMEM, Sigma, St. Louis, MO, USA) and used in the chemotactic activity assay.

\section{Ethical considerations}

This research project was approved by the Ethics Committee of the Dental School at the University of São Paulo, SP, Brazil, and written informed consent was obtained from all blood donors.

\section{Pulp capping materials}

The pulp capping materials used were: $\mathrm{Ca}(\mathrm{OH})_{2}$, Single Bond and MTA. The $\mathrm{Ca}(\mathrm{OH})_{2}$ paste (Merck, KGaA, Darmstadt, Germany) was prepared by mixing $1 \mathrm{~g}$ of powder with $200 \mu \mathrm{l}$ of distilled water. The adhesive system used was Single Bond (3M ESPE, St. Paulo, MN, USA), which was applied and light-polymerized for $20 \mathrm{~s}$ using a light source of $600 \mathrm{~mW} /$ $\mathrm{cm}^{2}$. Finally, the MTA (Pro-root, Dentsply-Tulsa, OK, USA) was prepared by mixing $1 \mathrm{~g}$ of powder with $350 \mu \mathrm{l}$ of distilled water.

\section{Experimental groups}
G I: Control
G II: $\mathrm{Ca}(\mathrm{OH})_{2}$
G III: Adhesive system
G IV: MTA

\section{Migrating assay}

Bipartite Transwell chambers (Corning Inc. New York, USA) were used to allow neutrophil migration. First, each substance was prepared and applied on the bottom of the lower chamber of the Transwell. Next, the lower chambers were filled with $1.5 \mathrm{ml}$ of fresh DMEM (Sigma). The filters were positioned, and the upper chambers were then filled with $500 \mu \mathrm{l}$ of the suspension of neutrophils $\left(2 \times 10^{5}\right.$ cells per chamber) (Figure 1). The Transwell chambers containing the neutrophils were then incubated for $48 \mathrm{~h}$ at $37^{\circ} \mathrm{C}$ in a humidified atmosphere containing $5 \% \mathrm{CO}_{2}$. This incubation time allowed the neutrophils to transmigrate through the filter into the lower chamber. Then, the media from the upper and lower chambers were collected separately. After centrifugation, the supernatants were stored for future analysis of cytokine production, and the 


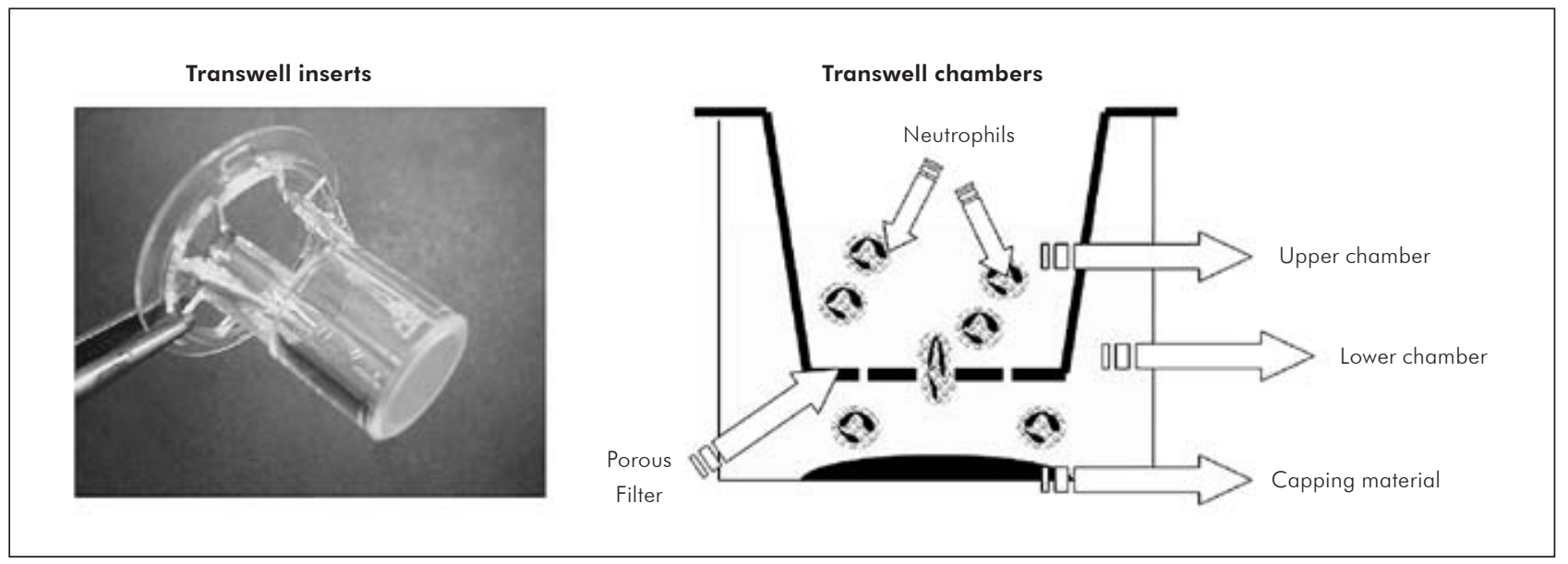

Figure 1 - Photograph of the Transwell insert and graphic representation of the migration assay showing how neutrophils migrate from the upper chamber to the lower chamber through the porous membrane.

cells in the pellets were counted. The cell count was carried out with a haemocytometer, using the Trypan blue dye exclusion assay. Briefly, the number of viable cells from each well chamber was obtained by the following mathematical equation:

$$
\mathrm{UC} \times \mathrm{D} \times 10^{4} / \mathrm{nSQ}
$$

where UC stands for unstained cell count (viable cells), D, the dilution of the cell suspension, and $\mathrm{nSQ}$, the number of haemocytometer squares counted.

The total viable cell number (cells from both chambers) was used to normalize cytokine production in each well. All assays were performed in triplicate.

\section{Cytokine production}

The supernatant obtained from the upper chamber after 48 hours of assay was used in the ELISA (Enzyme Linked Immuno Sorbent Assay) tests to detect and quantify IL-1 $\beta$ (RPN-5971, Biotrak, Amersham Pharmacia Biotech, Buckinghamshire, UK) and IL-8 (RPN-5969, Biotrak, Amersham Pharmacia Biotech). The ELISA tests were carried out following the manufacturer's instructions.

\section{Statistical analysis}

The data on viable cell number and cytokines concentration of all the experimental groups (in triplicate) were compared by ANOVA followed by Tukey's test as a post hoc test (SPSS 12.0 software, SPSS Inc., Chicago, IL, USA). The level of significance was $5 \%(\mathrm{p}<0.05)$.

\section{Results Cytokine production}

Figure 2 shows the production of IL-1 $\beta$. There were differences in the amount of IL- $1 \beta$ produced by the different experimental groups $(\mathrm{p}<0.001)$. The group treated with MTA presented a significantly higher production of IL-1 $\beta$ than the control (13-fold; $\mathrm{p}<0.01)$, the Single Bond and the $\mathrm{Ca}(\mathrm{OH})_{2}$ groups $(5.9$-fold, $\mathrm{p}<0.01)$. There were no significant differences in the amount of IL-1 $\beta$ produced by all other experimental groups $(\mathrm{p}>0.05)$.

The production of IL-8 was significantly greater in all groups when compared to that of the control group $(\mathrm{p}<0.001)$. The $\mathrm{Ca}(\mathrm{OH})_{2}$ induced the production of an amount of IL-8 similar to that of the other materials tested ( $\mathrm{p}>0.05)$. The adhesive system induced a higher production of IL- 8 than the MTA (1.2-fold, $\mathrm{p}<0.01$ ) (Figure 3).

\section{Discussion}

The release of inflammatory cytokines, such as IL-1 $\beta$ and IL- 8 , by neutrophils during the inflammatory process is important for tissue repair, including that which takes place in the dental pulp. By analyz- 


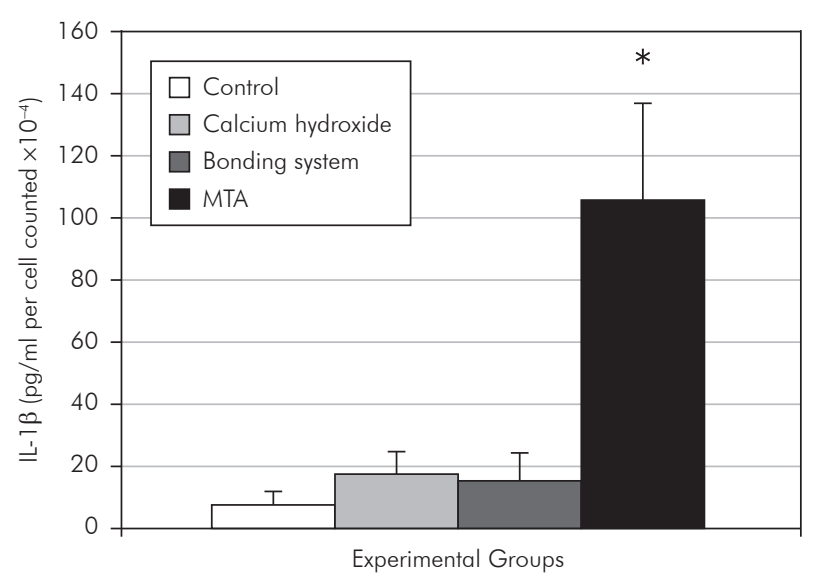

Figure 2 - Graphic representation of the concentration of IL-1 $\beta$ per cell for each test group (* means significantly higher than all other groups).

ing the effect of pulp capping materials $\left[\mathrm{Ca}(\mathrm{OH})_{2}\right.$, Single bond and MTA] on the release of these cytokines by migrating human neutrophils, the present study has demonstrated a significant increase in the production of IL-8, especially by cells under the influence of the adhesive system. On the other hand, only MTA was able to induce a significant increase in the production of IL- $1 \beta$.

The reparative process expected after dental pulp injury followed by protection with dental pulp capping materials depends on the inflammatory process. This process is influenced by the cytotoxicity of these materials, and also by their ability to induce cytokine production. Among the inflammatory cytokines, IL- 8 and IL- $1 \beta$ have already been found in the dental pulp. ${ }^{10-17}$ In fact, IL8, whose production is generally induced by bacteria, is one of the most important chemotactic cytokines. This cytokine is responsible for recruiting neutrophils, a process required to induce acute inflammation, and is also involved in determining the duration of the inflammatory process. ${ }^{16}$ This acute inflammation generally follows tissue injury. ${ }^{12,16,17} \mathrm{IL}-1 \beta$ is a proinflammatory cytokine that plays a major role in the cellular immune response produced just after tissue injury. ${ }^{1,13,17}$

It was previously shown that MTA causes neutrophils to be recruited into the mouse peritoneal cavity, and that this phenomenon was dependent on

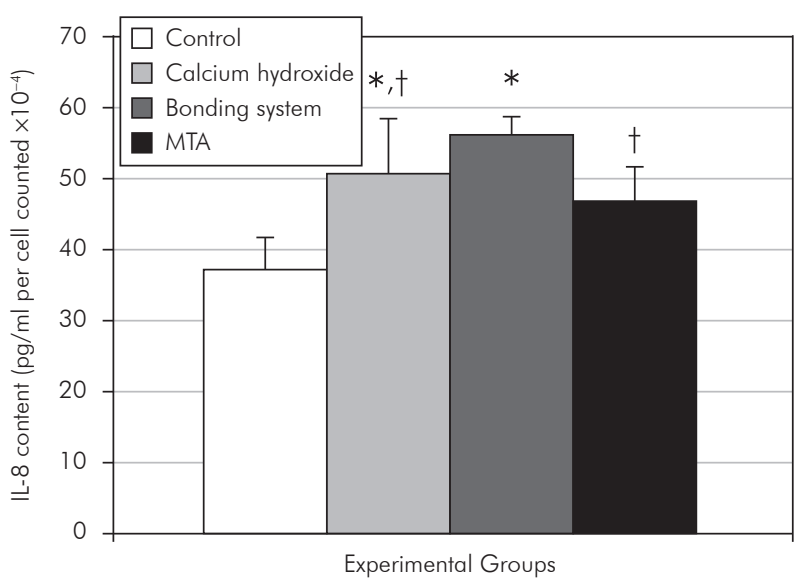

Figure 3 - Graphic representation of the concentration of IL-8 per cell for each test group ( ${ }^{*}$ and $†$ mean significantly higher than control; similar symbols indicate no statistical difference).

mast cells and macrophages through the release of inflammatory mediators. ${ }^{17}$ To mimic this situation with human neutrophils, Transwell chambers were used in order to allow neutrophils to migrate from one side of the insert to the other, towards the media at the bottom chamber, conditioned by the pulp capping materials tested. A similar functional assay was performed by Haglund et al. with mouse fibroblasts and macrophages. However, these authors were unable to detect neither IL- $1 \beta$ nor IL- 6 production by either type of cell. Few studies have been performed using human cells. ${ }^{18}$

The production of IL-1 $\beta$ was increased only in the presence of the MTA. In fact, other studies have already reported in vitro ${ }^{1,17-20}$ and in vivo ${ }^{12}$ that MTA is able to improve the production of IL- $1 \beta$ by macrophages, neutrophils and mast cells. This could have implications on the satisfactory effect of MTA after dental pulp exposure. Corroborating this hypothesis, Barkhordar et al. found that exogenous IL-1 $\beta$ induced a two-fold increase in collagen synthesis by healthy pulp fibroblasts. Thus, the fact that MTA induces neutrophils to produce IL- $1 \beta$ could result in a more organized dental pulp response after the injury, leading to a more favorable pulp repair. ${ }^{19}$

All tested materials induced the production of IL-8. This is an important finding, since it is known that all materials can induce different levels of acute inflammation in the pulp. ${ }^{3,4}$ Moreover, Single Bond 
was able to induce a significantly higher secretion of IL-8 than MTA. Since IL-8 is a potent neutrophil chemotactic protein, secretion of this cytokine by migrating neutrophils was expected. However, the secretion of too much IL-8 should not be stimulated because attraction of neutrophils in excess could perpetuate the inflammatory process, thus jeopardizing the expected subsequent repair process.

The stimulation of IL- 8 secretion, which would attract more neutrophils to the injured dental pulp, could explain our previous findings using other adhesive systems, where a mild to severe inflammatory response and no mineralized tissue formation were observed after direct pulp capping in human teeth. ${ }^{21}$

Moreover, it has been previously shown that Single Bond is cytotoxic to human dental pulp fibroblasts. ${ }^{22}$ In a recent study, this material also induced angiogenic growth factors. ${ }^{23}$ Thus, these results indicate a non-beneficial effect of adhesive systems used as pulp capping materials, at least in proximity to the dental pulp. On the other hand, MTA could be considered the material of choice for pulp capping, based on the improvement in the secretion of

\section{References}

1. Gomes AC, Gomes-Filho JE, Oliveira SHP. MTA-induced neutrophil recruitment: a mechanism dependent on IL-1, MIP2, and LTB4. Oral Surg Oral Med Oral Pathol Oral Radiol Endod. 2008 Sep;106(3):450-6.

2. Murray PE, Hafez AA, Windsor LJ, Smith CF, Cox AJ. Comparison of pulp responses following restoration of exposed and non-exposed cavities. J Dent. 2002 Jul-Aug;30(5-6):213-22 .

3. Accorinte ML, Loguercio AD, Reis A, Carneiro E, Grande RHM, Murata SS, et al. Response of Human Dental Pulp Capped with MTA and Calcium Hydroxide Powder. Oper Dent. 2008 Sep-Oct;33(5):488-95.

4. Koliniotou-Koumpia E, Tziafas D. Pulpal responses following direct pulp capping of healthy dog teeth with dentine adhesive systems. J Dent. 2005 Sep;33(8):639-47.

5. Takita T, Hayashi M, Takeichi O, Ogiso B, Suzuki N, Otsuka $\mathrm{K}$, et al. Effect of mineral trioxide aggregate on proliferation of cultured human dental pulp cells. Int Endod J. 2006 May; 39(5):415-22.

6. Nair PN, Duncan HF, Pitt Ford TR, Luder HU. Histological, ultrastructural and quantitative investigations on the response of healthy human pulps to experimental capping with mineral trioxide aggregate: a randomized controlled trial. Int Endod J. 2008 Feb;41(2):128-50.
IL-1 $\beta$ and on the lesser secretion of IL- 8 by neutrophils, combined to all the other biological advantages of this material.

With the ultimate goal of finding an ideal pulp capping material, further studies using this cell model and other cells related to the inflammatory and reparative processes are recommended to clarify the relationships between cytotoxic effects, cell migration and cytokine production.

\section{Conclusions}

It was concluded that only MTA was able to improve the secretion of IL- $1 \beta$, and all tested materials increased the secretion of IL-8. Thus, combined with all the other biological advantages of this material, MTA could be considered the material of choice for dental pulp capping.

\section{Acknowledgements}

This investigation was supported by Research Grant \# 02/10462-7 from the State of São Paulo Research Foundation (FAPESP).

7. Silva MJ, Vieira LQ, Paulino Sobrinho A. The effects of mineral trioxide aggregates on cytokine production by mouse pulp tissue. Oral Surg Oral Med Oral Pathol Oral Radiol Endod. 2008 May;105(5):e70-6.

8. Accorinte ML, Holland R, Reis A, Bortoluzzi MC, Murata SS, Dezan-Jr E, et al. Evaluation of Mineral Trioxide Aggregate and Calcium Hydroxide Cement as Pulp-capping Agents in Human Teeth. J Endod. 2008 Jan;34(1):1-6

9. Hjorth R, Jonsson AK, Vretblad P. A rapid method for purification of human granulocytes using percoll ${ }^{\circledR}$. A comparison with dextran sedimentation. J Immunol Methods. 1981 May;43(1):95-101.

10. Hosoya S, Matsushima K. Stimulation of interleukin-1 $\beta$ production of human dental pulp cells by Porphyromonas endodontalis lipopolysaccharide. J Endod. 1997 Jan;23(1):3942.

11. Nagaoka S, Tokuda M, Sakuta T, Taketoshi Y, Tamura M, Takada H, et al. Interleukin-8 gene expression by human dental pulp fibroblast in cultures stimulated with Prevotella intermedia lipopolysaccharide. J Endod. 1996 Jan;22(5):2406.

12. Jiang Y, Russell TR, Schilder H, Graves DT. Endodontic pathogens stimulate monocyte chemoattractant protein-1 
and interleukin-8 in mononuclear cells. J Endod. 1998 Feb;24(2):86-90.

13. Kuo ML, Lamster IB, Hasselgren G. Host mediators in endodontic exudates. I. Indicators of inflammation and humoral immunity. J Endod. 1998 Sep;24(9):598-603.

14. Levin LG, Rudd A, Bletsa A, Reisner H. Expression of IL-8 by cells of the odontoblast layer in vitro. Eur J Oral Sci. 1999 Apr;107(2):131-7.

15. Shimauchi H, Takayama S, Narikawa-Kiji M, Shimabukuro Y, Okada H. Production of interleukin- 8 and nitric oxide in human periapical lesions. J Endod. 2001 Dec;27(12):749-52.

16. Lertchirakarn V, Birner R, Messer HH. Effects of interleukin-1 beta on human pulpal fibroblast proliferation and collagen synthesis. J Endod. 1998 Jun;24(6):409-13.

17. Gomes AC, Gomes-Filho JE, Oliveira SHP. Mineral trioxide aggregate stimulates macrophages and mast cells to release neutrophil chemotactic factors: role of IL-1, MIP-2 and LTB4. Oral Surg Oral Med Oral Pathol Oral Radiol Endod. 2010 Mar;109(3):e135-42.
18. Haglund R, He J, Jarvis J, Safavi KE, SpEngberg LSW, Zhu Q. Effects of root-end filling materials on fibroblasts and macrophages in vitro. Oral Surg Oral Med Oral Pathol Oral Radiol Endod. 2003 Jun;95(6):739-45.

19. Barkhordar RA, Ghani QP, Russel TR, Hussain MZ. Interleukin-1 beta activity and collagen synthesis in human dental pulp fibroblasts. J Endod. 2002 Mar;28(3):157-9.

20. Ferreira DC, Brito DG, Cavalcanti BN. Cytokine production from human primary teeth pulp fibroblasts stimulated by different pulpotomy agents. J Dent Child (Chic). 2009 SepDec;76(3):194-8.

21. Demarco FF, Tarquinio SB, Jaeger MM, de Araújo VC, Matson E. Pulp response and cytotoxicity evaluation of 2 dentin bonding agents. Quintessence Int. 2001 Mar;32(3):211-20.

22. Cavalcanti BN, Rode SM, Marques MM. Cytotoxicity of substances leached or dissolved from pulp capping materials. Int Endod J. 2005 Aug;38(8):505-9.

23. Tran-Hung L, Laurent P, Camps J, About I. Quantification of angiogenic growth factors released by human dental cells after injury. Arch Oral Biol. 2008 Jan;53(1):9-13. 